\title{
Microsatellite DNA markers indicate three genetic lineages in East Asian indigenous goat populations
}

\author{
K. Nomura*, K. Ishii*, H. Dadi* ${ }^{*}$, Y. Takahashi*, M. Minezawa ${ }^{\ddagger}$, C. Y. Cho ${ }^{\S}$, Sutopo", \\ M. O. Faruque**, D. Nyamsamba ${ }^{\dagger \dagger}$ and T. Amano* \\ *Faculty of Agriculture, Tokyo University of Agriculture, 1737 Funako, Atsugi, Kanagawa, 243-0034, Japan; ${ }^{\dagger}$ Adami Tulu Agricultural \\ Research Center, PO Box 35, Ziway, Ethiopia; 'Genebank, National Institute of Agrobiological Science, 2-1-2 Kannondai, Tsukuba, \\ Ibaraki, 305-8602, Japan; ${ }^{\$}$ National Institute of Animal Science, Rural Development Administration, 4-1 San, Yongsan-ri, Unbong-eup, \\ Namwon-si, 590-830, Korea; "Faculty of Animal Science, Diponegoro University, J1.Prof. Soedorto, SH-Tembalang, Semarang, 50275, \\ Indonesia; ${ }^{* *}$ Department of Animal Breeding and Genetics, Bangladesh Agricultural University, 2202, Mymensingh, Bangladesh; \\ ${ }^{\dagger}$ Research Institute of Animal Husbandry, Mongolian Agricultural University, 210153, Zaisan, Ulan Bator, Mongolia
}

\section{Summary}

\begin{abstract}
The genetic differentiation and phylogenetic relationships of 18 indigenous goat populations from seven East Asian countries were analysed based on data obtained from 26 microsatellite DNA markers. The mean number of alleles (MNA) per population ranged from 2.5 to 7.6 , with an average of 5.8. Genetic variability estimated from MNA and heterozygosity $\left(H_{\mathrm{E}}\right.$ and $\left.H_{\mathrm{O}}\right)$ were relatively low in coastal and island populations. A heterozygous deficiency within populations $\left(F_{\mathrm{IS}}=0.054, \quad \mathrm{P}<0.001\right)$ and total inbreeding $\left(F_{\text {IT }}=0.181, P<0.01\right)$ were observed, and genetic differentiation in the populations $\left(F_{\mathrm{ST}}\right)$ was $13.4 \%$. The results of Bayesian model-based clustering and a neighbour-joining tree based on Nei's genetic distance showed that Asian goat populations could be subdivided into at least the following three genetic clusters: East Asian, Southeast Asian and Mongolian. These results are in close accordance with conventional morphological and geographical classifications and migration history.
\end{abstract}

Keywords genetic distance, genetic diversity, indigenous goats, microsatellite (MS) markers.

\section{Introduction}

According to archaeological records, goats are believed to be the earliest domesticated ruminants in the Fertile Crescent region of West Asia, dating back approximately 10000 years. Today, goats are well adapted to a variety of climatic conditions and have a wider geographical distribution than any other domestic animal. They are able to survive on marginal land, even in mountains and deserts or on plateaus and islands (Porter 1996). In 2009, there were approximately 868 million goats in the world, with the population having increased annually by 1.2 -fold of the number measured in 2000. More than half of the goats in the world are reared in Asia (FAOSTAT, http://

Address for correspondence

K. Nomura, Faculty of Agriculture, Tokyo University of Agriculture, 1737 Funako, Atsugi, Kanagawa 243-0034, Japan.

E-mail: meeme@nodai.ac.jp

Accepted for publication 12 October 2011 faostat.fao.org; Rischkowsky \& Pilling 2007). The majority of these animals are domestic or local breeds that are not developed for commercial purposes. However, they have become well adapted to the environment in each country, including tolerating severe climatic stress (Porter 1996), reproduction under poor management conditions and adaptation to a variety of forage qualities. During this decade, the domestic breeds have attracted attention, as they are valuable genetic resources, with conservation of domestic animal diversity being essential to meet future needs (Scherf 2000). From an economic standpoint, some Asian countries recently have become concerned about their indigenous goat populations. For example, cashmere wool from indigenous goats is a major export product in Mongolia (Takahashi et al. 2008) and Black Bengal goats are an important source of income for small farmers, who constitute the majority of the population in Bangladesh (Faruque et al. 2010). In Thailand, creation of a new goat breed has begun by crossbreeding their indigenous breed with some exotic breeds (Suwit et al. 2010). 
Studies on the genetic diversity of domestic goats using a maternal mitochondrial DNA marker have been conducted over the last few years throughout the Asian continent and the Old World (Luikart et al. 2001; Joshi et al. 2004; Naderi et al. 2007). These studies concluded that the domestic goat showed a weak phylogeographic structure. Using European and Middle Eastern breeds, Cañón et al. (2006) studied genetic diversity using nuclear DNA microsatellite (MS) markers. Several studies using MS markers revealed important information on genetic diversity in some Asian goat populations, although each study was performed regionally or within a country, such as in Southeast Asia (Barker et al. 2001), China (Li et al. 2002; Li \& Valentini 2004), India (Rout et al. 2008) or Mongolia (Takahashi et al. 2008).

In this study, we used MS markers to examine the genetic diversity and relationships among native Asian goat populations, ranging from Mongolia in the north to Indonesia in the south and from Bangladesh in the west to Japan in the east. The genetic specificity of each population becomes clear from genetic comparison between cross-border goat populations. This information may be valuable for maintaining diversity and genetic uniqueness of the genetic resource of each goat.

\section{Materials and methods}

\section{Sample collection and microsatellite markers}

Blood samples were collected from 450 goats that originated from seven countries [four East Asian (Japan, Korea, Taiwan and Mongolia), two Southeast Asian (the
Philippines and Indonesia) and one South Asian (Bangladesh) countries; Table 1]. The number of individual populations per country ranged from 1 to 7 , and the number of samples per population ranged from 20 to 30 unrelated animals within the original area of the population.

Fifty-three MS markers were tested, including 30 loci recommended by the International Society for Animal Genetics and FAO for evaluating goat genetic diversity (MoDAD marker set, Hoffman et al. 2004). Twenty-seven markers were excluded from further analyses, as described below. Of the $30 \mathrm{MoDAD}$ markers, after repeat testing, four (OarAE54, INRA063, SRCRSP15 and DRBP1) failed to amplify DNA fragments. Given the results of the EvensWatterson test for marker neutrality, eight markers (OarFCB048, SR-CRSP-9, SR-CRSP-5, ILSTS087, CSRD247, MCH2-DR, BM848 and BM4621) departed from neutrality $(P<0.05)$. Linkage disequilibrium between each pair of loci was estimated and resulted in exclusion of seven loci (INRAO23, SR-CRSP-7, SR-CRSP-3, SR-CRSP-24, SR-CRSP-25, SPS113 and SR-CRSP-23). To estimate the error rate of genotyping, $10 \%$ of the random samples were genotyped again and the results were compared with the original genotype (Pompanon et al. 2005). Eight loci (IDVGA37, OarFCB11, ILSTSO11, TGLA53, HUJ625, INRA081, IDVGA43 and BM6444) were estimated to have more than a $3 \%$ error rate in genotyping and were therefore excluded. The other 26 markers, listed in Table 2, were used in the statistical analyses.

The PCR amplification conditions have been described in a previous study (Dadi et al. 2008). Amplified fragments were separated using an ABI-PRISM 3100-Avant Genetic

Table 1 Diversity parameters in 18 Asian goat populations.

\begin{tabular}{|c|c|c|c|c|c|c|c|c|c|}
\hline Country & Population & Abbreviation & $n$ & TNA & MNA & $A R$ & $H_{\mathrm{E}}$ & $H_{\mathrm{O}}$ & $F_{\mathrm{IS}}$ \\
\hline Japan & Shiba & JS & 30 & 66 & 2.54 & 2.30 & 0.302 & 0.312 & -0.035 \\
\hline \multirow[t]{2}{*}{ Korea } & Southwest & KW & 25 & 136 & 5.23 & 4.69 & 0.535 & 0.531 & 0.008 \\
\hline & Southeast & $\mathrm{KE}$ & 25 & 95 & 3.65 & 3.30 & 0.388 & 0.334 & $0.143^{* * *}$ \\
\hline \multirow{2}{*}{ Taiwan } & West & TW & 20 & 136 & 5.23 & 5.06 & 0.615 & 0.563 & $0.087^{* * *}$ \\
\hline & East & $\mathrm{TE}$ & 20 & 138 & 5.31 & 5.09 & 0.613 & 0.579 & $0.057^{*}$ \\
\hline Philippines & Luzon and Mindoro & $\mathrm{PH}$ & 30 & 140 & 5.38 & 4.75 & 0.584 & 0.522 & $0.107^{* * *}$ \\
\hline \multirow[t]{3}{*}{ Indonesia } & Kambing Katjang Bali & IB & 25 & 113 & 4.35 & 3.82 & 0.407 & 0.368 & $0.099^{* * *}$ \\
\hline & Kambing Katjang Java & IJ & 30 & 125 & 4.81 & 4.26 & 0.502 & 0.419 & $0.168^{* * *}$ \\
\hline & Etawa & IE & 25 & 139 & 5.35 & 4.89 & 0.598 & 0.553 & $0.077^{* * *}$ \\
\hline \multirow[t]{2}{*}{ Bangladesh } & Black Bengal & BB & 30 & 165 & 6.35 & 5.52 & 0.601 & 0.578 & $0.039^{*}$ \\
\hline & Indian breed & $\mathrm{BI}$ & 20 & 180 & 6.92 & 6.41 & 0.673 & 0.642 & $0.047^{*}$ \\
\hline \multirow[t]{7}{*}{ Mongolia } & Zavkhan Buural & $M Z$ & 25 & 182 & 7.00 & 6.39 & 0.698 & 0.664 & $0.050^{* *}$ \\
\hline & Zalaajinst White & MW & 25 & 184 & 7.08 & 6.44 & 0.695 & 0.660 & $0.051^{* *}$ \\
\hline & Erchim Black & $\mathrm{ME}$ & 24 & 195 & 7.50 & 6.77 & 0.715 & 0.697 & 0.026 \\
\hline & Ulgii Red & $M U$ & 24 & 190 & 7.31 & 6.61 & 0.687 & 0.681 & 0.009 \\
\hline & Bayandelger & $M B$ & 23 & 177 & 6.81 & 6.32 & 0.688 & 0.661 & $0.039^{*}$ \\
\hline & Dorgon & MD & 24 & 197 & 7.58 & 6.89 & 0.715 & 0.707 & 0.012 \\
\hline & Sumber & MS & 25 & 164 & 6.31 & 5.81 & 0.690 & 0.673 & 0.025 \\
\hline
\end{tabular}

TNA, total number of alleles/population; MNA, mean number of alleles/locus; AR, allelic richness; $H_{E}$, heterozygosity estimates; $H_{O}$, heterozygosity observed; MS, microsatellite.

${ }^{*} P<0.05$

${ }^{*} P<0.01$;

$* * * P<0.001$ 
Table 2 Number of alleles, range of allele size and results of $F$-statistics for each 26 loci across the 18 goat populations.

\begin{tabular}{|c|c|c|c|c|c|c|}
\hline Locus & Chromosome $^{1}$ & Number of allele & Allele size & $F_{\mathrm{IS}}$ & $F_{\mathrm{IT}}$ & $F_{\mathrm{ST}}$ \\
\hline ВM3205 & 1 & 17 & $206-248$ & $0.090 * * *$ & $0.178 * * *$ & $0.097^{* * *}$ \\
\hline TCRVB6 & 1 & 15 & $222-254$ & 0.038 & $0.134 * * *$ & $0.099 * * *$ \\
\hline INRA040 & 2 & 19 & $210-290$ & $0.066^{* *}$ & $0.238 * * *$ & $0.185^{* * *}$ \\
\hline OarFCB20 & 2 & 13 & 78-116 & $0.149 * * *$ & $0.283 * * *$ & $0.158 * * *$ \\
\hline ILSTSO29 & 3 & 11 & $146-176$ & 0.005 & $0.109 * * *$ & $0.104^{* * *}$ \\
\hline MAF70 & 4 & 13 & $131-157$ & $0.080 * *$ & $0.201 * * *$ & $0.132 * * *$ \\
\hline ETH-10 & 5 & 6 & $201-215$ & $0.131 * *$ & $0.236 * * *$ & $0.120^{* * *}$ \\
\hline$B M 143$ & 6 & 13 & 90-118 & 0.056 & $0.169 * * *$ & $0.120^{* * *}$ \\
\hline INRABERN192 & 7 & 10 & $171-195$ & $0.083 * *$ & $0.214 * * *$ & $0.139 * * *$ \\
\hline MCM527 & 7 & 11 & $150-170$ & 0.017 & $0.166^{* * *}$ & $0.152 * * *$ \\
\hline ILSTSOO5 & 10 & 6 & $172-184$ & 0.018 & $0.127 * * *$ & $0.111 * * *$ \\
\hline CSSM030 & 13 & 5 & $156-168$ & 0.016 & $0.154 * * *$ & $0.141 * * *$ \\
\hline BM2934 & 14 & 14 & 78-116 & $0.070^{* *}$ & $0.208^{* * *}$ & $0.149 * * *$ \\
\hline MAF065 & 15 & 16 & $108-152$ & 0.035 & $0.188^{* * *}$ & $0.158^{* * *}$ \\
\hline HUJ614 & 16 & 10 & 149-181 & -0.007 & $0.165^{* * *}$ & $0.171 * * *$ \\
\hline MAF209 & 17 & 4 & 89-101 & 0.059 & $0.419 * * *$ & $0.382 * * *$ \\
\hline INRABERN185 & 18 & 12 & $162-286$ & 0.020 & $0.063^{* *}$ & $0.044 * * *$ \\
\hline HAUT14 & 18 & 11 & 139-171 & 0.035 & $0.095 * * *$ & $0.062 * * *$ \\
\hline BM1818 & 23 & 14 & $244-272$ & 0.035 & $0.158^{* * *}$ & $0.128^{* * *}$ \\
\hline$P 19$ (DYA) & 23 & 14 & $172-204$ & $0.066^{* *}$ & $0.167^{* * *}$ & $0.109 * * *$ \\
\hline INRABERN172 & 26 & 12 & $231-257$ & 0.051 & $0.215^{* * *}$ & $0.172 * * *$ \\
\hline CSSMO43 & 27 & 11 & $226-256$ & $0.051^{*}$ & $0.142 * * *$ & $0.097 * * *$ \\
\hline RM044 & 29 & 16 & 79-109 & $0.073 * * *$ & $0.202 * * *$ & $0.139 * * *$ \\
\hline$S R-C R S P 8$ & Unknown & 13 & $211-241$ & 0.017 & $0.141 * * *$ & $0.126^{* * *}$ \\
\hline OarCP34 & Unknown & 13 & $104-128$ & $0.052^{*}$ & $0.161^{* * *}$ & $0.115^{* * *}$ \\
\hline \multirow[t]{2}{*}{$S R-C R S P 26$} & Unknown & 12 & $121-147$ & $0.063 * *$ & $0.184 * * *$ & $0.129 * * *$ \\
\hline & All & 311 & & $0.054 * * *$ & $0.181 * * *$ & $0.134^{* * *}$ \\
\hline
\end{tabular}

${ }^{1}$ From Vaiman et al. 1996 and GOATMAP DATABASE http://locus.jouy.inra.fr/cgi-bin/lgbc/mapping/common/intro2.pl?BASE=goat.

${ }^{*} P<0.05$,

${ }^{*} * P<0.01$,

${ }^{* * *} P<0.001$.

Analyser (Applied Biosystems), and allele sizes relative to an internal size standard (GS400HD) were determined using GENEMAPPER ${ }^{\text {TM }} 3.5$ (Applied Biosystems).

\section{Statistical analyses}

Allele frequencies, mean number of alleles (MNA), and observed $\left(H_{\mathrm{O}}\right)$ and expected $\left(H_{\mathrm{E}}\right)$ heterozygosities were calculated for each population using the Microsatellite Toolkit (Park 2001). Allelic richness (AR) per population (i.e. the corrected mean allele number reflected in the standardised sample size) was calculated using FSTAT 2.9.3 (Goudet 2001). Wright's F-statistics [within-population inbreeding $\left(F_{\mathrm{IS}}\right)$, total inbreeding $\left(F_{\mathrm{IT}}\right)$ and among-population genetic differentiation $\left(F_{\mathrm{ST}}\right)$ ] for each locus and overall population and pairwise $F_{\mathrm{ST}}$ values were obtained from FSTAT using the variance-based method of Weir \& Cockerham (1984). The significance values for pairwise $F_{\mathrm{ST}}$ were adjusted using the Bonferroni correction method. Deviation from the Hardy-Weinberg equilibrium (HWE) was determined using Fisher's exact test in GENEPOP version 4.0 (Rousset 2008). Unbiased estimates of exact $P$-values were obtained using the Markov Chain Monte Carlo (MCMC) algorithm (Guo \& Thompson 1992). The linkage disequilibrium between each pair of loci was tested with GENEPOP.
A neutrality test was performed to detect the selective pressure on a locus and exclude those loci under selective pressure using POPGENE 1.31 (Yeh et al. 1999).

Genetic relationships among individuals and populations were estimated by constructing neighbour-joining (NJ) trees using the shared allele distance $\left(D_{\mathrm{AS}}\right)$ between individuals (Jin \& Chakraborty 1994) and pairwise $D_{\mathrm{A}}$ distances (Nei et al. 1983), with 1000 bootstraps being implemented in POPULATions 1.2.30 (Langella 1999). The generated trees were visualised using NJPLOT and UNROOTED (Perrière \& Gouy 1996).

The population structure and degree of admixture were inferred using Bayesian model-based clustering of multilocus genotypes to obtain the number of parental populations $(K)$ for a given sample with STRUCTURE 2.3.1 (Pritchard et al. 2000). The admixture proportions of individual samples were estimated and assigned a $K$ value. To obtain a representative value of $K$ for data modelling, we performed 20 independent runs for each value from 1 to 23 with burn-in and MCMC iterations of 30000 and 50000 each with default settings and an admixture model, followed by $\Delta K$ statistics (Evanno et al. 2005). The results of independent runs were aligned using CLUMPP version 1.1.2 (Jakobsson \& Rosenberg 2007) and visualised using DISTRUCT version 1.1 (Rosenberg 2004). 


\section{Results}

\section{Genetic diversity}

The 26 markers listed in Table 2 amplified 311 alleles that ranged from four alleles at MS MAF209 to 19 alleles at INRA040, with an average of 12 alleles per locus. The genetic variability quantified as MNA, AR, $H_{\mathrm{E}}$ and $H_{\mathrm{O}}$ for each goat population is presented in Table 1 . The lowest MNA was 2.54 in the Japanese Shiba population, and the highest was 7.58 in the Mongolian Dorgon. AR based on 16 individuals per population ranged from 2.30 in Shiba to 6.89 in Dorgon. The estimated $H_{\mathrm{E}}$ per population ranged from 0.302 in Shiba to 0.715 in Erchim Black and Dorgon. $H_{O}$ ranged from 0.312 in Shiba to 0.707 in Dorgon. $H_{\mathrm{E}}$ was comparatively high in the Mongolian and Indian populations. Relatively low genetic variability $\left(H_{\mathrm{E}}<0.6\right)$ was observed in populations from Indonesia, the Philippines, and Korea. The Indonesian Etawa, a crossbreed between native Kambing Katjang and exotic Indian Jamnapari (Porter 1996), showed higher genetic variation than the original native populations. $H_{O}$ was lower than $H_{\mathrm{E}}$ in all the populations studied, except Shiba. Deviation from HWE was statistically significant $(P<$ 0.05 ) for 53 out of 468 locus-population combinations (Table S1). Ten populations (Korean east, Taiwan west, Philippines, Indonesian Bali, Java, Etawa, Bangladeshi Black Bengal, Mongolian Zavkhan Buural, Zalaajinst White and Bayandelger) showed significant deviations from HWE $(P<0.05)$.

\section{Genetic differentiation and relationships among populations}

The mean estimates of $F$-statistics obtained by jack-knifing over 26 loci are as follows: $F_{\text {IS }}=0.054 \pm 0.007$, $F_{\text {IT }}=0.181 \pm 0.009$ and $F_{\text {ST }}=0.134 \pm 0.007$ (Table 2). The overall $F_{\text {IS }}$ value was low, but highly significant $(P<0.001)$. This was most likely due to non-random mating within populations. Twelve loci significantly $(P<0.05)$ contributed to the $F_{\text {Is }}$ estimate, and all loci influenced $F_{\text {IT }}(P<0.01)$. $F_{\text {IS }}$ for the populations showed a significant deficit of heterozygotes in 12 populations, ranging from 0.039 in Mongolian Bayandelgel to 0.168 in Indonesian Java (Table 1). As shown in Table 1, the lowest genetic variation was observed in Shiba goats, possibly because of their small population size in Japan. Currently, Shiba goats are used as laboratory animals only at a few research stations in Japan. For $F_{\text {IS }}$, one to seven loci contributed significantly to heterozygous deficiency in all the populations (Table S1). On the other hand, one to two loci showed significant excess of heterozygotes in some goat populations.

All pairwise $F_{\mathrm{ST}}$ values were significantly different, with the exception of pairs between some Mongolian populations $(P>0.05)$ (Table 3$)$. The pairwise $F_{\mathrm{ST}}$ values were comparatively low for within-country populations, except those for Indonesian Etawa. Although geographical distances between goat populations are greater in Mongolia than in other countries, the $F_{\mathrm{ST}}$ values in Mongolian populations were notably lower than those of other countries. As reported previously, this result may indicate a high level of gene flow among Mongolian populations (Takahashi et al. 2008). In between-country relationships, the $F_{\mathrm{ST}}$ values between Indian and Mongolian populations were low, ranging from 0.067 to 0.081 (Table 3).

An NJ tree based on $D_{\mathrm{A}}$ was used to portray the degree of genetic relationships among goat populations (Fig. 1). The tree divided Asian goats into three clusters: Southeast Asia, East Asia and Mongolia. The East Asian cluster was divided into sub-clusters of Japan-Korea and Taiwan. As indicated in Fig. S1, the NJ tree based on $D_{\mathrm{AS}}$ showed that, with few exceptions, each individual animal was clustered to its population of origin.

Graphical displays of the results from the sTRUCTURE analysis are presented in Fig. 2. The sTRucture analysis did not clearly return genetic clusters with maximum likelihood (ln $\operatorname{Pr}[G \mid K]$ ) and reached a plateau beyond $K=7$. The $\Delta K$ values obtained were 16.8 at $K=2,328.8$ at $K=3,2.4$ at $K=4,23.5$ at $K=5,1.8$ at $K=6$ and 1.8 at $K=7$. At $K=2$, there was a transition from the North Asian population (yellow) to the South Asian population (blue) (Fig. 2). At $K=3$, the $\Delta K$ value reached a maximum and the East Asian cluster (red) was separated. At $K=3$, the Japan (red), Indonesia-Philippine (blue) and Mongolia (yellow) populations showed three distinct clusters, whereas the Taiwanese and Bangladeshi populations showed an admixture pattern with a Mongolian cluster, which showed lowlevel population differentiation. At $K=5$, no admixture clusters were observed for within-country populations; the five clusters were Japanese-Korea, Taiwan, PhilippineIndonesia, Bangladesh-India and Mongolia. Generally, the clustering pattern observed in the STRUCTURE analysis was similar to the classification of the $\mathrm{NJ}$ tree based on $D_{\mathrm{A}}$.

\section{Discussion}

In this study, we estimated the genetic diversification of the extensive Asian indigenous goat populations using MS DNA markers. Our data showed that the genetic variation estimated by MNA and AR in within-country populations of Asian goats was lower than that of European breeds, which was 5.2-9.1 MNAs, with an average of 7.1 and 6.1-7.9 AR values (Cañón et al. 2006). Genetic variation was comparatively high in Asian inland populations (Mongolian and Indian goats) and low in populations that ranged from Southeast Asian islands and the southeastern or eastern edge of the continent (Black Bengal in Bangladesh, Kambing Katjang in Indonesia and Philippine and Korean goats). 


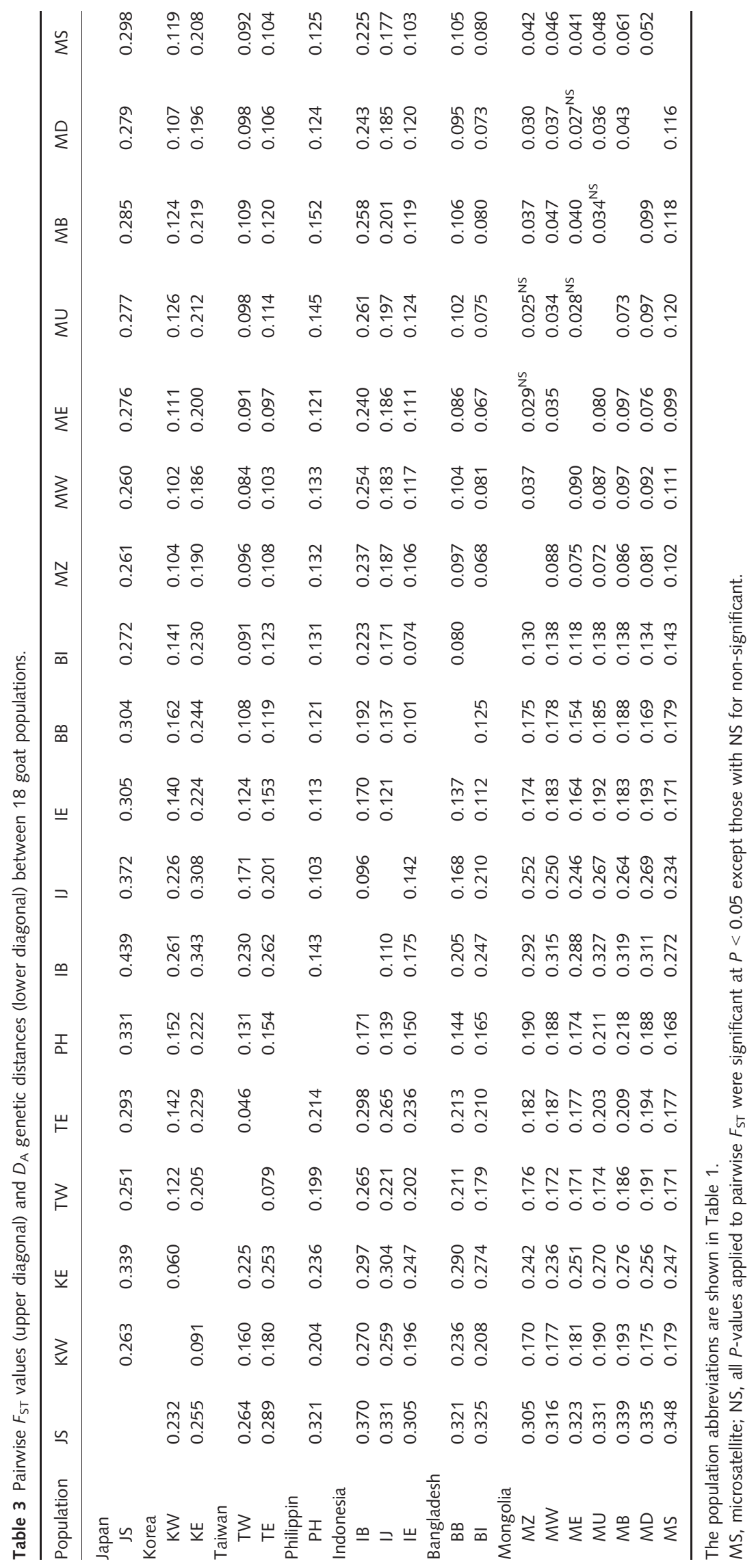




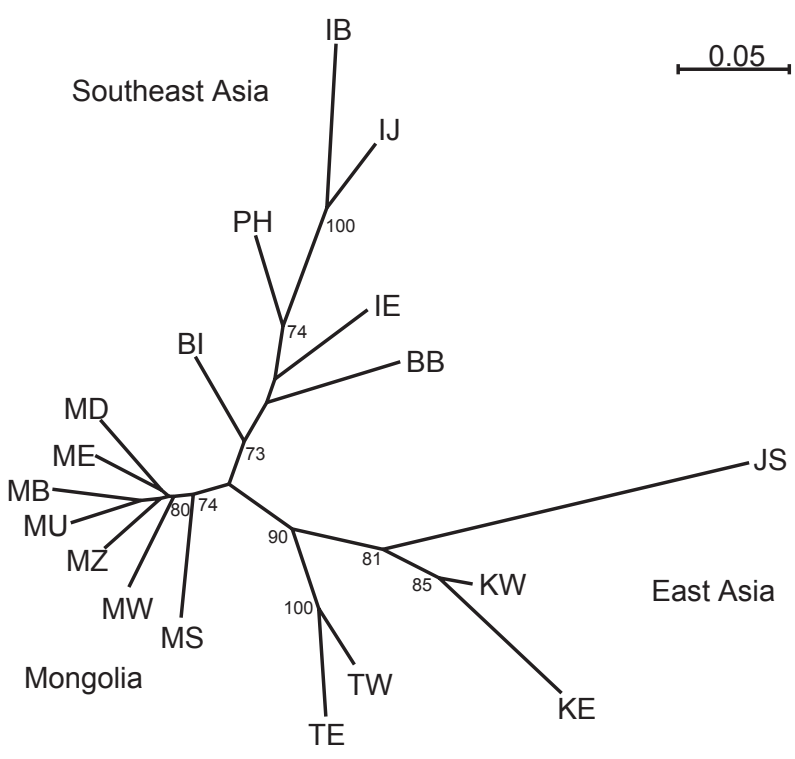

Figure 1 Neighbour-joining (NJ) tree of 18 goat populations from seven Asian countries, based on Nei's genetic distance $\left(D_{A}\right)$. The population abbreviations are shown in Table 1. The numbers on the nodes indicate the bootstrap values (\%) obtained from 1000 replications.

The average $F_{\text {ST }}$ of the breeds studied was 0.13 , higher than that of the European breeds, which had a mean value of 0.07 (Cañón et al. 2006). The Indonesian Kambing Katjang and Japanese populations showed higher pairwise $F_{\mathrm{ST}}$ values than the mean, suggesting that the two populations showed higher genetic differentiation than other populations. The islands of Indonesia and Japan are located farthest from the goat domestication centre of West Asia, and it is most likely a reason for their high genetic differentiation.

A subdivision of the Asian goat populations containing at least three clusters was observed commonly in the NJ tree based on $D_{\mathrm{A}}$ and stRucture model-based clustering of Southeast Asian, East Asian and Mongolian clusters. The populations that were assigned admixture clusters in Structure clustering at $K=3$ were the Taiwanese and Bangladeshi populations. When assigned to their specific clusters at $K=5$, these two populations showed low-level population differentiation based on $D_{\mathrm{A}}$ and $F_{\mathrm{ST}}$ values. Nozawa (1991) classified goats around the world into three categories or types based mainly on morphology and history of domestic goat migration: Bezoar, Savannah and Nubian types. The Bezoar type is the most general or unspecialized type, with erect ears and a straight and unraised nose bridge, the Savannah type with twisted horns is adapted to dry environments, and the Nubian type is the milk goat with drooping ears and an accipitrine nose. According to Devendra \& Nozawa (1976), dispersion of these three types across Asia from the domestication centre occurred chronologically in the above order through two main routes. First, the Bezoar-type, and second, the Savannah-type goats migrated via the Silk Road. Finally, the Nubian-type goat, which had descended from the Savannah type, migrated through the Khybar Pass to the Indian subcontinent (Devendra \& Nozawa 1976).

Comparison of the classifications of the MS markers used in this study showed that the East Asian cluster corresponded morphologically to the Bezoar type and the Mongolian cluster corresponded to the Savannah type. The STRUCTURE clustering results showed that some Indian and Taiwanese contained the same portion of the Mongolian cluster. Taiwanese goats are the direct descendants of the goats indigenous to southern China, Guangdong and Fujian, which were introduced by immigrants in the seventeenth century (Porter 1996). Therefore, it is believed that the Savannah type reached Mongolia with a genetic influence from the Indian subcontinent and China. The Indian population analysed in this paper corresponded morphologically to the Nubian type and was categorized as in the same cluster as the Black Bengal and Kambing Katjang, the Southeast Asian dwarf goats, with a 73\% bootstrap value by an NJ tree on genetic distance $\left(D_{\mathrm{A}}\right)$. The Philippines was the northernmost country for distribution of the Southeast clustered goats, and genetically different goats were found in the neighbouring island of Taiwan.

The results of MS DNA markers in genetic subdivisions of East Asian indigenous goats were consistent with the migration history of goats and also with morphological and geographical classifications. This study provides valuable information on the genetic structure of Asian indigenous goats for future genetic improvement and conservation programmes in each country. Appropriate goat-breeding programmes are required to maintain the genetic uniqueness of each population and to minimize inbreeding as well as unnecessary gene flow among populations.

\section{Acknowledgements}

We thank Dr N. Okumura, Society for Techno-innovation of Agriculture, Forestry and Fisheries (STAFF of the

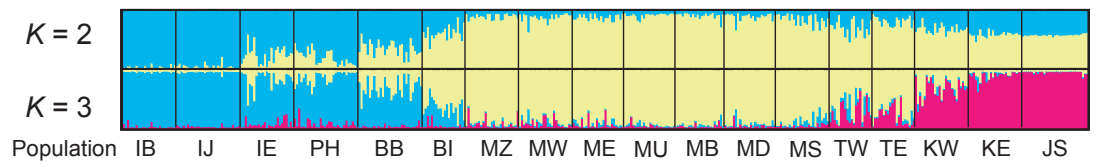

Figure 2 Model-based clustering of 18 Asian goat populations assuming $K=2$ and 3 . The population abbreviations are shown in Table $1 . K$ is the number of assumed clusters. Individuals are represented by a vertical bar divided into estimated proportions of $K$ colours. 
Institute), and Dr T. Hayashi, National Institute of Agrobiological Sciences, for their contribution to the statistical analyses. This work was supported by the Advanced Research Project Type A, Tokyo University of Agriculture, No. 02, 2006-2008, and the Grant-in-Aid for Scientific Research (B) no. 19405043, 2007-2009 from Japan Society for the Promotion of Science. The authors are grateful for the suggestions and comments from the editor and anonymous reviewers.

\section{References}

Barker F.S.J., Tan G.S., Moore S.S., Mukherjee K.T., Matheson L.J. \& Selvaraj S.O. (2001) Genetic variation within and relationships among populations of Asian goats (Capra hircus). Journal of Animal Breeding and Genetics 118, 213-33.

Cañón J., García D., García-Atance A.M., Obexer-Ruff G., Lenstra A.J., Ajmone-Marsan P., Dunner S. \& The Econogene Consortium. (2006) Geographical partitioning of goat diversity in Europe and the Middle East. Animal Genetics 37, 327-34.

Dadi H., Tibbo M., Takahasji Y., Nomura K., Hanada H. \& Amano T. (2008) Microsatellite analysis reveals high genetic diversity but low genetic structure in Ethiopian indigenous cattle populations. Animal Genetics 39, 425-31.

Devendra C. \& Nozawa K. (1976) Goat in South East Asia - their status and production. Zeitschrift für Tierzüchtung und Züchtungsbiologie: Organ der Reichsarbeitsgemeinschaft Tierzucht im Forschungsdienst 93, 101-20.

Evanno G., Regnaut S. \& Goudet J. (2005) Detecting the number of clusters of individuals using the software STRUCTURE: a simulation study. Molecular Ecology 14, 2611-20.

Faruque M., Hasnath M., Khan M., Takahashi Y., Nomura K. \& Amano T. (2010) Current status of animal genetic resources and livestock production in Bangladesh. Report of the Society for Researches on Native Livestock 25, 1-34.

Goudet J. (2001) FSTAT, a program for Windows (95 and above) to estimate and test gene diversities and fixation indices (version 2.9.3). Available at http://www.unil.ch/izea/softwares/ fstat.html

Guo S.W. \& Thompson E.A. (1992) Performing the exact test of Hardy-Weinberg proportions for multiple alleles. Biometrics 48 , 361-72.

Hoffman I., Marsan P.A., Barker J.S.F., Cothran E.G., Hanotte O., Lenstra J.A., Milan D., Weigend S. \& Simianer H. (2004) New MoDAD marker sets to be used in diversity studies for the major farm animal species: recommendations of a joint ISAG/ FAO working group. In: Proceedings of the 29th International Conference on Animal Genetics. Meiji University, Tokyo, Japan.

Jakobsson M. \& Rosenberg N.A. (2007) cLuMPP: a cluster matching and permutation program for dealing with label switching and multimodality in analysis of population structure. Bioinformatics 23, 1801-6.

Jin L. \& Chakraborty R. (1994) Estimation of genetic distance and coefficient of gene diversity from single-probe multilocus DNA fingerprinting data. Molecular Biology and Evolution 11, 120-7.

Joshi M.B., Rout P.K., Mandal A.K., Tyler-Smith C., Singh L. \& Thangaraj K. (2004) Phylogeography and origin of Indian domestic goats. Molecular Biology and Evolution 21, 454-62.
Langella O. (1999) Populations 1.2.30: population genetic software CNRS UPR 9034. Available at http://bioinformatics.org/ $\sim$ tryphon/populations/

Li X.L. \& Valentini A. (2004) Genetic diversity of Chinese indigenous goat breeds based on microsatellite markers. Journal of Animal Breeding and Genetics 121, 350-5.

Li M.H., Zhao S.H., Bian C. et al. (2002) Genetic relationships among twelve Chinese indigenous goat populations based on microsatellite analysis. Genetics, Selection, Evolution 34, 729-44.

Luikart G., Gielly L., Excoffier L., Vigne J.D., Bouvet J. \& Taberlet P. (2001) Multiple maternal origins and weak phylogeographic structure in domestic goats. Proceedings of the National Academy of Science of the United states of America 98, 5927-32.

Naderi S., Rezaei H.R., Taberlet P., Zundel S., Rafat S.A., Naghash H.R., El-Barody M.A., Ertugrul O., Pompanon F. \& Econogene Consortium (2007) Large-scale mitochondrial DNA analysis of domestic goat reveals six haplogroups with high diversity. PLoS ONE 2, 2 .

Nei M., Tajima F. \& Tateno Y. (1983) Accuracy of estimated phylogenetic trees from molecular data II. Gene frequency data. Journal of Molecular Evolution 19, 153-70.

Nozawa K. (1991) Domestication and history of goat. In: Genetic Resources of Pig, Sheep and Goat (Ed. by K. Maijala), pp. 391-403. Elsevier Science Publishers B.V., Amsterdam, The Netherlands.

Park S.D.E. (2001) The Excel Microsatellite Toolkit: Excel tools for diploid or haploid microsatellite data. Available at http://animalgenomics.ucd.ie

Perrière G. \& Gouy M. (1996) WWW-query: an on-line retrieval system for biological sequence banks. Biochimie 78, 364-9.

Pompanon F., Bonin A., Bellemain E. \& Taberlet P. (2005) Genotyping errors: causes, consequences and solutions. Nature Review Genetics 6, 847-59.

Porter V. (1996) Goats of the World. Farming Press, Ipswich, UK.

Pritchard J.K., Stephens M. \& Donnelly P. (2000) Inference of population structure using multilocus genotype data. Genetics 155, 945-59.

Rischkowsky B. \& Pilling D. (2007) The State of the World's Animal Genetic Resources for Food and Agriculture. FAO, Rome.

Rosenberg N.A. (2004) DIsтRUCT: a program for the graphical display of population structure. Molecular Ecology Notes 4, 137-8.

Rousset F. (2008) GENEPOP'007: a complete re-implementation of the GENEPOP software for Windows and Linux. Molecular Ecology Resources 8, 103-6.

Rout P.K., Joshi M.J., Mandal A., Laloe D., Singh L. \& Thangaraj K. (2008) Microsatellite-based phylogeny of Indian domestic goats. BMC Genetics 9, 11.

Scherf B.D. (2000) World Watch List for Domestic Animal Diversity, 3rd edn. FAO, Rome.

Suwit A., Nomura K., Oishi T. \& Amano T. (2010) Goat genetic resources and breeding strategies in Thailand. The Journal of Animal Genetics 38, 41-8.

Takahashi H., Nyamsamba D., Mandakh B., Zagdsuren Y., Amano T., Nomura K., Yokohama M., Ito S. \& Minezawa M. (2008) Genetic structure of Mongolian goat populations using microsatellite loci analysis. Asian-Australasian Journal of Animal Science 21, 947-53.

Vaiman D., Schibler L., Bourgeois F., Oustry A., Amigues Y. \& Cribiu E.P. (1996) A genetic linkage map of the male goat genome. Genetics 144, 279-305. 
Weir B.S. \& Cockerham C.C. (1984) Estimating F-statistics for the analysis of population structure. Evolution 38, 1358-70.

Yeh F.C., Yang R. \& Boyle T. (1999) Popgene version 1.31: Microsoft Window-based freeware for population genetic analysis. Available at http://www.ualberta.ca.

\section{Supporting information}

Additional supporting information may be found in the online version of this article.

Figure S1 Unrooted NJ tree of individual goats constructed by $D_{\text {AS. }}$ The tree shows that each individual clustered to its population of origin, with the exception of the Mongolian population. The seven Mongolian indigenous populations formed one Mongolian cluster.

Table S1 $F_{\text {IS }}$ for each locus in 18 Asian goat populations.

As a service to our authors and readers, this journal provides supporting information supplied by the authors. Such materials are peer-reviewed and may be re-organized for online delivery, but are not copy-edited or typeset. Technical support issues arising from supporting information (other than missing files) should be addressed to the authors. 